\title{
A educação escolar, dinâmica de formação do caráter e a concretização do processo de formação dos valores pessoais
}

\author{
Célia Regina da Silva \\ Júlia Mazinini Rosa
}

\section{RESUMO}

Este texto tem como objetivo desvelar as determinações que tornam a educação escolar uma das atividades humanas responsáveis por compor a dinâmica do processo de formação de valores orientadores das atitudes dos indivíduos. Iniciamos estabelecendo relações entre a sociedade, a educação escolar e o processo de formação dos indivíduos. Em seguida apresentamos características gerais da dinâmica de formação do caráter segundo a psicologia histórico-cultural - explicitado como produto da atividade concreta dos indivíduos - de modo a expor alguns determinantes que recaem sobre a formulação dos valores orientadores das condutas individuais. Neste processo, buscamos tornar evidente a inevitável incidência da educação escolar sobre a formação da conduta dos estudantes. Finalizamos com a análise de situações concretas observadas no cotidiano de uma escola de educação infantil e extraídas da tese de doutoramento de uma das autoras (Silva, 2017). Apresentamos, então, algumas perspectivas para a formulação intencional e sistematizada de práticas educativas em que se busque transmitir valoração positiva em relação aos interesses coletivos universais como condição para o efetivo desenvolvimento individual.

Palavras-chave: Educação Escolar; Valores; Formação pessoal.

\section{ABSTRACT \\ School education, dynamics of character's formation and the process of forming personal values}

This paper aims to unveil the determinations that make school education one of the human activities which are responsible for creating the formation of values and dynamics that guide the attitudes of individuals. We started by establishing relationships between society, school education, and the formation of individuals. Then we present general characteristics of the character formation's dynamics according to historical-cultural psychology - explained as a product of the concrete activity of individuals - to expose some determinants that fall on the formulation of the guiding values of individual conduct. In this process, we seek to make evident the inevitable impact of school education on the formation of student's conduct. We conclude with the analysis of concrete situations observed in a field study on an early childhood school and extracted from the doctoral thesis of one of the authors (Silva, 2017). We present, then, some perspectives to corroborate intentionally and systematized educational practices towards the transmission of positive valuation related to universal collective interests as a condition for effective individual development.

Keywords: School Education; Values; Personal Formation.

\section{INTRODUÇÃO}

O problema da influência da educação escolar na formação dos valores pessoais dos alunos e alunas vêm sendo amplamente debatido por diversos setores da sociedade. Seja por posicionamentos em defesa da necessidade de uma suposta neutralidade dos conteúdos a

\section{Sobre os autores}

C. R. S.

https://orcid.org/0000-00028010-6803

Universidade do Estado de Minas Gerais - Belo Horizonte, MG crsilvau@gmail.com

\section{J. M. R.}

https://orcid.org/0000-0002-

2207-1446

Faculdade de Ciências e Letras (FCL) da Universidade Estadual Paulista Júlio de Mesquita Filho, (UNESP), Campus Araraquara Araraquara, SP

jrmazinini@gmail.com

\section{Direitos Autorais}

Este é um artigo de acesso aberto e pode ser reproduzido livremente, distribuído, transmitido ou modificado, por qualquer pessoa desde que usado sem fins comerciais. 0 trabalho é disponibilizado sob a licença Creative Commons CC-BY-NC.

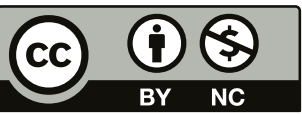




\section{MLE INTERACÃO EM PSICOLOGIA}

serem transmitidos pela escola, sob a alegação de que caberia somente à família promover a formação dos valores pessoais, seja por iniciativas que buscam organizar e sistematizar os conteúdos mais diretamente relacionados com a formação pessoal dos alunos, evidenciadas pela presença de orientações vinculadas à formação de habilidades e competências socioemocionais no documento curricular norteador das práticas a serem adotadas pela educação básica em âmbito nacional, que é a Base Nacional Curricular Comum (BNCC).

A oficialização desse conteúdo por meio da BNCC expressa não apenas o reconhecimento da importância da formação emocional, ou seja, o reconhecimento da educabilidade das emoções dos indivíduos, como também, principalmente, o reconhecimento da responsabilidade da educação escolar sobre esse aspecto da formação humana. Apesar de discordarmos da fundamentação que sustenta a abordagem desse conteúdo no referido documento por nos alinharmos às reflexões presentes em Silva (2018), consideramos necessário ressaltar que, contraditoriamente, a explicitação desse tema em um documento oficial abre caminhos interessantes para seu aprofundamento junto às redes de ensino, ainda que em perspectivas divergentes.

No presente texto, estabelecemos relações entre sociedade e educação escolar para apontarmos algumas determinações constitutivas do processo de formação dos valores que orientam atitudes dos indivíduos nas relações sociais, destacando alguns fatores associados à interferência da educação escolar sobre o processo de formação emocional e sobre o processo de formação de valores dos estudantes.

Pautando-nos em uma visão materialista-dialética, postulada pela psicologia histórico-cultural, buscamos contribuir para resgatar a concreticidade da interferência da educação escolar na formação dos sujeitos. Trata-se de um esforço para retirar do âmbito da "opinião" a discussão sobre a quem caberia a formação pessoal dos indivíduos, de modo a confrontar falsas dicotomias expressas em afirmações em que se defende que a "escola deve ensinar e a família deve educar". Alicerçadas na cisão entre razão e emoção, tais afirmações apregoam uma suposta "neutralidade" da escola com relação à formação dos valores pessoais dos alunos e alunas, baseando-se em concepções reducionistas e naturalizantes e, em muitos casos, pseudocientíficas em relação ao processo de formação do psiquismo humano e, por vezes, acabam por orientar diversas práticas desenvolvidas no contexto escolar.

Em contraposição a essas perspectivas, apontaremos algumas relações e determinações que conferem concreticidade ao processo de formação do psiquismo humano, evidenciando a impossibilidade de dissociarmos a educação escolar de seu papel, inerentemente formativo, no que se refere à conduta dos indivíduos na sua relação com o mundo.

\section{SOCIEDADE, EDUCAÇÃO ESCOLAR E FORMAÇÃO DOS INDIVIDUOS}

Propomos, como ponto de partida para caminharmos na reflexão sobre a inevitável interferência da atividade escolar na formação dos indivíduos, a análise de alguns determinantes que compõem os elos entre sociedade, educação escolar e formação dos indivíduos. Para tanto, faz-se necessária a compreensão de que o ser humano, na sua condição ontogenética e filogenética, foi se constituindo por meio da sua atividade vital, o trabalho, e que essa atividade, necessariamente, engendra relações. Ou seja, nossas relações sociais são, sob um ponto de vista ontológico, relações de produção, pois foi a necessidade de produzir e reproduzir a vida que condicionou a existência individual à atividade coletiva. A partir dessa necessidade, os indivíduos humanos, ao longo de sua história, tiveram que estabelecer relações entre si e o processo de complexificação dessas relações impôs a necessidade de regulamentação de sua dinâmica. Nesse sentido cabe destacar que:

[...] no longo período da história social, marcado pela divisão das sociedades em classes antagônicas, as relações de produção existentes entre as classes fundamentais caracterizam-se pela divisão social do trabalho, acarretando que a objetivação do ser humano e a apropriação dos resultados dessa objetivação ocorressem sob formas que impediram que a totalidade da riqueza material e não material fosse posta a serviço da realização e do desenvolvimento da totalidade dos seres humanos (Saviani, 2015, p. 21).

Sendo assim, o processo de complexificação das relações sociais foi sendo conduzido de modo que o processo produtivo, até o presente momento, estruturou-se sob o antagonismo de classes. Tal aspecto constitui-se como uma das determinações que interferem na formulação dos modos de regulamentar o comportamento dos indivíduos, visto que impõe a dominação de uma classe sobre a outra como condicionante das relações sociais, incidindo sobre a dinâmica de formulação da ética e da moral, que são diretamente vinculadas aos valores a serem transmitidos pelos grupos para seus membros.

Esse processo de regulamentar, ou seja, de estabelecer regras para orientar a conduta dos indivíduos na sociedade, vincula-se diretamente à formação dos valores pessoais ao passo que requer que os grupos definam a valoração a ser atribuída para os diferentes tipos de conduta que, em última instância, corresponde ao que será considerado certo ou errado, bom ou ruim, nas atitudes adotadas pelos indivíduos.

Diante do exposto, ao explicitarmos condicionantes relacionados à necessidade social de incidir diretamente sobre a formação dos indivíduos, cabe situarmos a educação escolar como atividade que emerge no bojo da dinâmica de organização das sociedades divididas em classes. Saviani (2002) 


\section{M." INTERACÃO EM PSICOLOGIA}

destaca a educação escolar como atividade mediadora na relação entre indivíduo e sociedade e situa a escola como instância social que expressa a gênese da tomada de consciência pelo ser humano no que se refere ao reconhecimento da educação como atividade intencionalmente voltada para fınalidades previamente estabelecidas:

Entendida desse modo, a intencionalidade educativa pode ser considerada como a dimensão teleológica da ação educativa, a qual se constitui como a parte do conteúdo do pensamento referente às relações que o professor estabelece entre o aluno e a sociedade, conforme suas concepções a respeito dessa relação. Portanto, em cada ação educativa, estão contidas as expectativas que o professor carrega em relação à formação de cada aluno, cujo substrato engendra valores relativos ao lugar a ser ocupado por esse aluno nas relações sociais. Ainda que alguns professores não consigam explicitar tal expectativa por meio da linguagem ou ainda não tenham sequer refletido a respeito disso, o conteúdo do pensamento, ou seja, a intencionalidade que direciona seus atos educativos fundamenta-se na projeção que ele faz do aluno no que se refere à sua inserção na totalidade social (Silva, 2017, p. 69).

Partindo dessas premissas, considera-se que a sociedade burguesa, ao instituir-se por meio de um processo revolucionário derrubando um conjunto de valores vigentes até então, assume a defesa dessa forma de organização da vida humana como sendo universal, ou seja, o modelo burguês de sociabilidade passa a ser apontado como o modelo geral para a humanidade, instituindo os valores burgueses como referência orientadora da conduta de todos os seres humanos.

Coutinho (2010) mostra que essa condição da sociedade burguesa revolucionária se transforma numa condição reacionária, porque, a partir do momento em que a burguesia consegue empreender a revolução e ocupar esse lugar de modelo para as relações humanas, ela passa a produzir e a atuar para manter o modelo que atende aos seus interesses de classe como modelo universal para os seres humanos em sua totalidade, contradizendo algumas das principais ideias que defendeu para derrubar o modelo de sociedade contra o qual se insurgiu:

0 desafio que se colocava à classe burguesa era a necessidade de defender a igualdade formal entre os indivíduos e, ao mesmo tempo, disseminar o princípio da proteção à propriedade privada como valor universal, propondo que o fato de ter ou não ter a propriedade dos meios de produção seria fruto de uma casualidade existencial, a qual poderia (ou não) vir a ser superada por meio do esforço individual (Silva, 2017, p. 75).

A educação tem papel central nessa transição entre os valores que prevaleciam no modo de vida feudal e os valores defendidos pelo modelo burguês. No feudalismo, havia uma série de valores e de ideias que sustentavam determinadas práticas, as quais tiveram que ser superadas e, para que os indivíduos rompessem com os valores que sustentavam todas essas práticas, a sociedade burguesa teve que organizar um processo educativo intencionalmente voltado para esse fim, ou seja, traçar como deve ser a educação desse novo ser humano, o indivíduo burguês.

Aqui explicita-se o elo entre formação dos indivíduos e a educação escolar, pois ela é uma mediação particular, entre tantas outras, para que o indivíduo se insira e atue na sociedade, ao mesmo tempo em que, de forma dialética, apropria-se dos conteúdos historicamente acumulados pelos que o antecederam, pois: "tendo em vista que é o trabalho que define a essência humana, podemos considerar que está aí a referência ontológica para se compreender e reconhecer a educação como formação humana" (Saviani, 2015, p. 132). É por meio de sua atividade vital que o ser humano se diferencia dos outros animais, visto que não se comporta somente por quê; ele se comporta para. Ou seja, age orientado pela intencionalidade de seus atos na medida em que, além de reagir aos estímulos que o afetam como fazem todos os animais, também age teleologicamente, visto que consegue agir em função da projeção de um resultado futuro.

A educação escolar, ao instituir-se como uma das atividades mediadoras da relação entre o indivíduo e a sociedade confere concretude à intencionalidade coletiva e sistematicamente instituída com relação ao indivíduo que se quer formar em cada sociedade, sempre em conformidade com o tipo de relações de produção vigente. Apesar de inicialmente ter exercido um papel revolucionário, a intencionalidade educativa da sociedade, que tomou os interesses burgueses como universais, foi tornando-se uma intencionalidade educativa "reacionária". Mas o que quer dizer isso? Trata-se de uma intencionalidade que está comprometida com a adaptação das pessoas a esse modelo de sociedade, sem questionamentos sobre as condições que o modelo burguês oferece no que se refere ao desenvolvimento do potencial individual para o conjunto dos seres humanos.

Fundamentando-se na sociabilidade burguesa, o professor toma o modelo de sociabilidade humana existente e o considera como natural do ser humano, ou seja, o professor não questiona os valores vigentes por julgar que essa é a única sociabilidade possível, entendendo que sua tarefa é formar indivíduos adaptados a essa ordem social.

Para justificar a razão de ensinar algo para a criança, o professor pode questionar: é assim que tem que ser? Quais conteúdos estão sendo transmitidos por meio dessa atividade? Que valores estão contidos nessa estratégia didática? Tomemos, como exemplo, a formação de filas no cotidiano escolar. Se o professor deixa de fazer esses questionamentos, toma a fila como algo natural. Então, quando se adota, de forma natu- 


\section{H MTERAC̄OAEM PSICOLOGIA}

ralizada, determinado comportamento humano como parte da tarefa de ensinar, sem analisar os efeitos que determinada atividade produzirá na formação da conduta de alunos e alunas, estamos diante de uma intencionalidade reacionária, porque está sustentando atos educativos cegamente voltados para adaptar alunos e alunas às coisas como elas são.

Essa intencionalidade, expressa no ato educativo de formar a fila, quando executado de forma naturalizada, vincula-se ao modo como a sociedade burguesa entende que as relações sociais devem ser organizadas nesse modelo de sociedade. A educação escolar, como atividade mediadora, induz à execução de atos educativos vinculados a essa intencionalidade reacionária sempre que a sociabilidade burguesa é tomada como modelo universal. Esses atos educativos, no que lhes concerne, vão interferir na formação do indivíduo, formando seu caráter, sua conduta moral no âmbito singular e esse indivíduo, por sua vez, vai devolver o resultado deste processo formativo em "atos individuais" - ele vai se comportar, vai apresentar uma conduta individual que o caracteriza. Tudo isso se dá de forma extremamente dinâmica e complexa.

Diante do exposto, enfatizamos que as relações sociais são a fonte e o destino dos atos individuais: é de lá que eles saem e é para lá que eles vão. E são essas relações sociais (necessariamente reguladas pelo modo de produção vigente) que buscam conformar determinados atos - e não outros nos indivíduos. No modelo burguês de sociabilidade humana, determinadas condutas vão ser condenadas, outras serão valorizadas e a educação, seja ela escolar ou a própria atividade educativa mais ampla, terá papel fundamental no processo de formação dos valores que vão orientar a conduta dos indivíduos, visto que o conteúdo do psiquismo humano é produto de sua atividade concreta.

\section{PSICOLOGIA HISTÓRICO-CULTURALE A CONCRETICIDADE DA INTERFERENNCIA DA ATIVIDADE ESCOLAR NA FORMAÇÃO PESSOAL}

A partir da apresentação de alguns determinantes constitutivos das intervinculações entre sociedade, educação escolar e formação dos indivíduos, para que possamos analisar a influência da educação escolar na formação de valores, faz-se necessário ampliarmos a compreensão sobre o processo de formação do psiquismo individual, tendo em vista situarmos os valores pessoais como fator interveniente na dinâmica de funcionamento psíquico dos sujeitos, bem como a educação escolar como uma atividade que exerce um tipo específico de influência nesse processo.

Iniciaremos essa reflexão fundamentando-nos na psicologia histórico-cultural cujo escopo teórico-metodológico nos instrumentaliza para uma análise concreta da dinâmica que caracteriza a gênese, o desenvolvimento e o funcionamento do psiquismo e na pedagogia histórico-crítica como a teoria pedagógica que, em consonância com a mesma fundamentação, nos fornece subsídios para compreendermos os nexos entre os processos de ensino e de aprendizagem e a dinâmica psíquica. Baseando-nos nesses fundamentos, tomaremos como ponto de partida para a reflexão sobre o psiquismo humano e o processo de formação de valores, a lei geral do desenvolvimento psíquico proposta por Vygotski (2006), que afirma que o desenvolvimento do psiquismo humano se dá do coletivo (interpsíquico) para o individual (intrapsíquico). Transpondo essa lei para o processo de formação de valores, temos que os valores instituídos como hegemônicos tendem a tornar-se valores individuais por serem espontaneamente internalizados pelo indivíduo por meio de muitas atividades nas quais se insere.

Portanto, os valores possuem uma dimensão geral e é a partir dela, por meio de sua atividade no interior das relações sociais, que cada indivíduo internaliza o conjunto de valores que orienta sua conduta. A seguir discorreremos sobre a transformação dos valores coletivos em valores individuais, analisando a relação entre ética, moral e traços de caráter com base na dialética entre singular-particular-universal como elucidada na Figura 1:

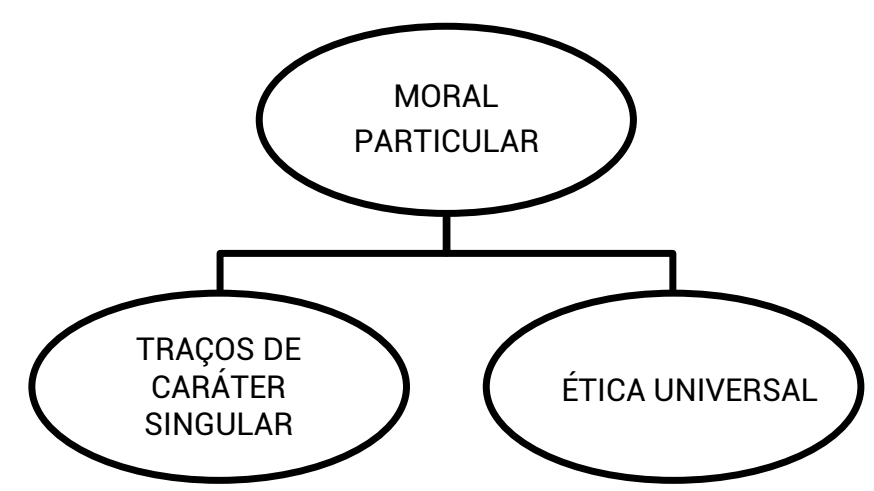

Figura 1. Diagrama da dialética entre traços de caráter-moral-ética

A figura ilustra que a dimensão universal da regulação da conduta individual vincula-se à ética, ao passo que a dimensão particular dessa regulação de relações interpessoais está associada à moral, e os traços de caráter dos indivíduos manifestam a dimensão singular, que confere materialidade ao movimento que se dá entre essas três dimensões da conduta individual. É a partir do aprofundamento do conceito de caráter, segundo a psicologia histórico-cultural, que compreenderemos a dialética entre ética-moral-caráter, analisando a dinâmica de formação do caráter e sua vinculação com o conjunto de valores que sustentam as relações de produção vigentes. 


\section{H. INTERACÃO EM 4T. PSICOLOGIA}

O termo caráter já foi alvo de inúmeros estudos em psicologia, mas, assim como personalidade, foi sendo abandonado, justamente por estar associado a concepções naturalizantes que tipificam os indivíduos, contribuindo para classificar e categorizar as pessoas. Vygotski (2006) mostra que, em geral, os estudos caractereológicos tomam o caráter como manifestação social de determinantes biológicos presentes nos indivíduos. Assim, limitam-se a descrever os tipos de caráter e formular hipóteses sobre os aspectos biológicos associados a cada um deles. Tais estudos corroboram a visão presente no senso comum de que o caráter dos indivíduos é estático, produto de características orgânicas, sofrendo pouca ou nenhuma interferência do contexto em que o indivíduo se encontra.

Mas o conceito de caráter na psicologia histórico-cultural não tem conotação de uma forma biológica de ação no mundo, moralmente louvável ou condenável. Nessa perspectiva, o caráter é entendido como uma dimensão mais regular da personalidade, que se forma por meio de atividade social. Krutetski (1960) postula que temperamento, caráter e capacidades são propriedades da personalidade que se desenvolvem sob interferência das relações sociais em que os indivíduos se inserem ao longo de seu desenvolvimento.

Vygotski (2006) acrescenta que os traços de caráter são caminhos que vão sendo forjados a partir do conjunto de atividades do indivíduo em sua luta para ocupar um lugar nas relações sociais, os quais tornam-se regulares ao ponto de constituírem-se como tendências que caracterizam aquele funcionamento individual. É o caráter que garante que haja em cada um de nós, como seres únicos e irrepetíveis, uma dimensão regular, ainda que essa regularidade não seja perene, que ela possa ser transitória, conforme o conjunto de relações e atividades às quais o indivíduo encontra-se submetido. 0 autor ressalta que o processo de constituição dessa regularidade é determinado socialmente e origina-se a partir do reflexo condicional:

Estudo sobre os reflexos condicionais não só dá a deus o que é de deus e a César o que é de César. Ele mostra que o momento motor, dinâmico, que empurra o desenvolvimento e provoca mudança está exatamente nas condições que reconstroem experiências hereditárias. A reação inata é só material e seu destino depende das condições formativas nas quais terá que se revelar. Na base inata podem se criar infinita e variavelmente (Vygotski, 2006, p. 2).

Sem negar os elementos orgânicos que interferem na formação dos traços do caráter, o autor desvela as determinações sociais desse processo. Vygotski (2006), ao discutir a questão do caráter, usa a expressão "dinâmica de formação do caráter", evidenciando que o caráter se constitui em um movimento dinâmico de intercâmbio entre processos subjetivos e as condições objetivas de vida. No entanto, essa dinamicidade não exclui uma estabilidade, ainda que transitória, visto que o caráter expressa uma regularidade que não é imutável, pois está condicionada às relações sociais, constituindo-se como uma base para a personalidade.

Assim, os traços de caráter representam regularidades da conduta individual, forjadas no contexto de relações interpessoais nas quais nos inserimos como seres singulares, mediadas pela relação com o contexto histórico e com as condições concretas de vida. Condições estas que são, ao mesmo tempo, reguladas pelo que está posto como valores nas relações interpessoais de cada um, bem como pelo que se apresenta como valores universais das relações humanas em cada momento histórico. Esses são os elos entre o caráter, a ética e a moral, apresentados aqui com o intuito de evidenciar que, mesmo o caráter sendo a expressão de regularidades manifestas pelo indivíduo, tais regularidades não se instituem no psiquismo individual desvinculadas do que está posto como referência dos valores da ética e da moral vigentes na sociedade.

Vygotski (2006) enfatiza que essa forma de compreender o caráter, como manifestação individual de um processo que é coletivo, expressa a coerência metodológica da psicologia histórico-cultural com relação ao método materialista-dialético:

Essencialmente, esta compreensão de fenômenos psicológicos não só do passado, mas do futuro não significa nada além da exigência dialética - aceitar os fenômenos em permanente movimento, descobrir nos fenômenos suas tendências, seu futuro, determinado por seu presente. Assim como na esfera da história nós nunca entenderemos até o fim a essência do regime capitalista se o tomarmos estaticamente, fora da tendência de seu desenvolvimento, fora de sua relação necessária com o regime futuro, enxergado em suas entranhas. Assim, na esfera da psicologia nunca entenderemos até o fim a personalidade humana se a analisarmos estaticamente, como uma soma de revelações, condutas, etc., sem um único plano de vida desta personalidade, sem sua linha dominante, que transforma a história de vida do ser humano de uma série de episódios desconexos e entrecortados num processo biográfico único e relacionado (Vygotski, 2006, p. 4).

Ao postular os traços de caráter como tendências da conduta individual que se constituem a partir das relações sociais mais amplas, os autores da psicologia histórico-cultural invertem a lógica predominante nas perspectivas naturalizantes, centradas em descrever as caraterísticas orgânicas inatas como causa das tendências de comportamento. Coerentemente com a ideia mencionada anteriormente de que o ser humano, além de se comportar "porque", se comporta "para", Vygotski (2006) destaca a interdependência entre a constituição das tendências individuais e as tendências universais de conduta vigentes em cada momento histórico, ressaltando que a compreensão da complexidade do psiquismo 


\section{H. INTERACÃO EM PSICOLOGIA}

humano requer estudos que busquem captá-lo em seu movimento para identificar, a partir de seu funcionamento atual, suas perspectivas futuras e destaca que:

A perspectiva psicológica do futuro é a possibilidade teórica da educação. A criança por sua natureza revela-se sempre incompleta em comparação com o adulto; sua posição, desde o início, dá razão para o desenvolvimento nela de sentimento de fraqueza, insegurança e dificuldade. A criança, durante longos anos, permanece inadaptável para a existência independente e nesta inadaptação e incômodo da infância está a raiz do seu desenvolvimento. A infância é a época de insuficiências e compensações pela vantagem, ou seja, de conquista de posições com relação ao social. No processo desta conquista o ser humano como um determinado biótipo transforma-se em ser humano como tipo social, um organismo animal constitui-se numa personalidade humana. O domínio deste processo social natural é chamado de educação (Vygotski, 2006, p. 8).

Com base nessa concepção, considera-se a educação escolar como atividade socialmente produzida e cuja função vincula-se não somente à necessidade de transmissão dos conhecimentos sistematizados às novas gerações, mas, principalmente, à intencionalidade social e coletivamente instituída que orienta os rumos sobre o tipo de indivíduo que se pretende formar, tendo em vista os rumos futuros da humanidade.

Ressaltamos que todo ato educativo tem uma dimensão teleológica a partir da qual projeta-se um resultado futuro a ser manifesto pelos indivíduos que foram alvo da intenção de educar e, em função do alcance desse resultado, quem busca educar repete determinados atos até que possa constatar seu êxito. Nesse sentido, Saviani (2005, p. 20) afırma que:

[...] só se aprende, de fato, quando se adquire um habitus, isto é, uma disposição permanente, ou, dito de outra forma, quando o objeto de aprendizagem se converte numa espécie de segunda natureza. $E$ isso exige tempo e esforços por vezes ingentes. A expressão segunda natureza me parece sugestiva justamente porque nós, que sabemos ler e escrever, tendemos a considerar esses atos como naturais. Nós os praticamos com tamanha naturalidade que sequer conseguimos nos imaginar desprovidos dessas características. Temos mesmo dificuldade em nos recordar do período em que éramos analfabetos. As coisas se passam como se se tratasse de uma habilidade natural e espontânea. E, no entanto, trata-se de uma habilidade adquirida e, frise-se, não de modo espontâneo. A essa habilidade só se pode chegar por um processo deliberado e sistemático.

0 autor, ao propor uma teoria pedagógica fundada no materialismo dialético, qual seja, a pedagogia histórico-crítica, situa o papel específico que a educação escolar cumpre no processo de desenvolvimento humano, diferenciando a educação escolar de outras práticas educativas. Com base nesses preceitos e em concordância com Martins (2013a), ressaltamos a consonância entre a pedagogia histórico-crítica e a psicologia histórico-cultural no que se refere ao papel da educação escolar na formação dos indivíduos. Nesse sentido, a autora revela:

Ao defender que cabe à educação escolar disponibilizar um tipo específico de conhecimento, a saber, os conhecimentos clássicos, essa teoria (pedagogia histórico-crítica) [grifo nosso] coloca em questão não apenas a natureza dos conteúdos a serem transmitidos na escola, mas também a forma pela qual ela deva se dar. [...] Por conseguinte, a seleção de conteúdos e a forma organizativa da aprendizagem, para a psicologia histórico-cultural não são fatores que possam ser secundarizados. Da mesma forma, para a pedagogia histórico-crítica há que se identificar, no ato educativo, sob quais condições a aprendizagem opera verdadeiramente a serviço do desenvolvimento dos indivíduos (Martins, 2013a, p. 134).

Do exposto, desvela-se que é por meio da forma e do conteúdo do ato educativo que a incidência da educação sobre o desenvolvimento individual pode efetivar-se. Na educação escolar, a especificidade do ato educativo vincula-se à função precípua do professor, sendo fator interveniente na dinâmica de formação do caráter (Silva, 2017) que corresponde àquelas reações que se estruturaram como típicas daquele sujeito e cuja constituição vincula-se ao conjunto de valores que orientam a conduta do indivíduo.

\section{A CONCRETICIDADE DOS ATOS EDUCATIVOS EM CONTEXTO ESCOLAR E O PROCESSO DE FORMAÇÃO DE VALORES}

A partir da reflexão sobre a função social atribuída à educação escolar no que se refere à sua interferência na dinâmica de formação das regularidades que caracterizam o funcionamento psíquico singular, buscamos situar cada ato educativo como manifestação singular que confere concretude à intencionalidade que orienta a projeção futura para a qual esse ato está voltado. Com base nesses pressupostos, analisamos exemplos de situações concretas, observadas no cotidiano de uma escola de educação infantil, extraídas de Silva (2017).

Para análise de alguns determinantes que conferem concreticidade aos atos educativos, tomaremos como ponto de partida a III tese sobre Feuerbach:

A doutrina materialista de que os seres humanos são produtos das circunstâncias e da educação, [de que] seres humanos transformados são, portanto, produtos de outras circunstâncias e de uma educação mudada, esquece que as circunstâncias são transformadas precisamente pelos seres humanos e que o educador tem ele próprio de 


\section{H*' INTERACÃO EM LTPSICOLOGIA}

ser educado. Ela acaba, por isso, necessariamente, por separar a sociedade em duas partes, uma das quais fica elevada acima da sociedade (por exemplo, em Robert Owen). A coincidência do mudar das circunstâncias e da atividade humana só pode ser tomada e racionalmente entendida como práxis revolucionante (Marx, 1845, seção 3, para. 1).

Destacamos essa tese com o intuito de enfatizar que $o$ ato educativo ocorre em determinadas circunstâncias, as quais encerram aspectos universais e singulares que compõe a intencionalidade de quem o realiza. Como vimos, o conteúdo da consciência do educador é a singularização do conteúdo da circunstância em que esse educador se encontra inserido. Desse modo, as ações de quem educa afetam quem está sendo educado por meio da dinâmica entre a forma e o conteúdo de cada ato em que a conduta do educando for objeto de intervenção do educador, quer ele tenha clareza sobre como seus atos afetarão os educandos ou não. Afınal, qualquer ato humano constitui-se como unidade afetivo-cognitiva que se revela por meio de sua forma e conteúdo, visto que é impossível "qualquer relação entre sujeito e objeto isentar-se de componentes afetivos" (Martins, 2013b, p. 243).

A natureza dos atos educativos manifestos na relação entre o professor e o aluno associa-se à própria função social da escola que, como vimos, institui uma nova circunstância para a humanidade no que se refere à intencionalidade dos processos educativos. Como instância social responsável pela transmissão dos conhecimentos historicamente acumulados pela humanidade para as novas gerações, cabe principalmente à escola o ensino dos conhecimentos científicos. Reside aí sua especificidade em relação a outras formas de educação no que diz respeito ao tipo de interferência que exerce sobre o psiquismo dos alunos e alunas.

Essa assertiva requer que abordemos, ainda que de forma sintética, os pressupostos da psicologia histórico-cultural com relação ao processo de formação de conceitos no psiquismo individual. Vygotski (2001) diferencia dois tipos de conceitos que se instituem no processo de desenvolvimento do pensamento humano, interpondo-se na relação dos indivíduos com a realidade. Para o autor, o pensamento humano estrutura-se a partir de conceitos cotidianos, que são internalizados de forma espontânea por meio da experiência cotidiana dos indivíduos, e de conceitos científicos, cujo processo de internalização é mais complexo, pois exige um ensino sistemático e intencional.

De acordo com Vygotski (2001), a internalização dos conceitos científicos envolve processos de complexificação do psiquismo que não são exigidos na apreensão dos conceitos cotidianos. A proposição do autor subsidia a defesa de Saviani (2005) quanto à tarefa específica da escola de ensinar os conhecimentos universalmente relacionados com o aprimoramento da compreensão do indivíduo sobre a realidade humana. Sendo assim, estabelece-se uma relação hierárquica entre os processos desencadeados por esses dois tipos de conceitos no que diz respeito ao grau de complexificação do funcionamento do sistema interpsíquico que ambos engendram. Entretanto, convém esclarecer que:

Estas concepções de inferioridade e superioridade dos conceitos cotidianos e científicos fizeram com que o autor explicitasse a formação de conceitos como um processo que caminha, simultaneamente, de "cima para baixo" e de "baixo para cima": ao longo do ensino, os conceitos se enriqueceriam onde são debilitados, assim, os cotidianos adquiririam uma sistematização superior e os científicos se impregnariam da riqueza do sentido e da experiência pessoal (Rosa, 2018, p. 61).

A educação escolar é a atividade em que, primordialmente, devem ocorrer os processos de enriquecer de sistematicidade os conceitos cotidianos e de enriquecer de sentido pessoal os conceitos científicos, visto que a educação escolar é uma atividade que, mesmo estando sistematicamente voltada para o ensino de conceitos científicos, não está isenta em relação à sua inevitável interferência no processo de internalização de conceitos cotidianos:

Ademais, haja vista a própria dimensão sistêmica do psiquismo, o percurso intencional ao qual a formação de conceitos científicos atende, exigindo sobretudo o domínio da própria conduta, interpõe-se na construção de mecanismos necessários à contenção ou educação das respostas emocionais reflexas. Além disso, reiteramos que o autodomínio do comportamento não se identifica com o livre atendimento das vontades individuais, mas com o autodomínio conscientemente orientado por finalidades humanizadoras, isto é, identificado com a fruição de funções psíquicas superiores (Martins, 2013b, p. 307).

Ocorre que a formação de conceitos, tanto no que se refere aos conceitos cotidianos quanto com relação aos conceitos científicos, efetiva-se por meio de processos psíquicos que são constituídos por uma unidade afetivo-cognitiva. Isso se concretiza devido à indissociabilidade entre conceitos e juízos, pois todo conceito é internalizado no bojo de relações interpessoais e a transmissão dos conteúdos associados a cada conceito se dá sob uma forma que, necessariamente, encerra juízos, ou seja, contém julgamentos que resultam da síntese do conjunto de sensações associadas a esse conceito pela pessoa que o está transmitindo. Desse modo, não há como desvincular o processo de formação de conceitos da formação emocional e, consequentemente, da formação de valores pessoais, já que os juízos associados a cada conceito se apoiam no sistema de valoração que, inevitavelmente, se manifesta nas condições de ensino do referido conceito. 


\section{M." INTERACÃO EM PSICOLOGIA}

Martins (2013b) afırma que o ato educativo, cuja função é ampliar a capacidade de alunos e alunas de analisar a realidade em que se encontram para orientar suas ações no mundo, poderá concretizar um compromisso com as máximas possibilidades de desenvolvimento de alunos e alunas à medida que for executado, tendo em vista a consideração das necessidades de seu destinatário. Ao sintetizar as ideias da autora com relação à proposição da tríade conteúdo-forma-destinatário, Rosa (2018) afırma:

Quanto aos conteúdos escolares, a questão que se apresenta é quais conteúdos são necessários à compreensão cada vez mais desmistificada e objetiva do mundo. Estes conteúdos devem, necessariamente, obedecer à relação conteúdo-forma-destinatário, o que significa que, no trabalho pedagógico, tanto conteúdo quanto forma se alteram com o destinatário, ou seja, com as possibilidades de ensino já criadas pelo desenvolvimento psíquico do indivíduo (p. 61).

Entretanto, cabe destacar que a interferência dos atos realizados pelo professor no processo de formação do aluno não ocorre somente nas circunstâncias em que ele busca, conscientemente, ensinar algo que quer que o aluno aprenda, pois, sua influência sobre o psiquismo do aluno efetiva-se por meio da forma e do conteúdo manifestos em cada um de seus atos dirigidos aos alunos. Com isso, buscamos enfatizar que nem todo ato realizado por professores em contexto escolar garantirá a promoção do desenvolvimento dos alunos na direção almejada pelo professor.

Para elucidar, por meio da análise de situações concretas, as reflexões anteriormente desenvolvidas, apresentaremos alguns exemplos de práticas pedagógicas extraídas dos registros de observação realizada em uma escola de educação infantil que atende crianças de 0 a 5 anos, em função da produção da tese de doutoramento (Silva, 2017) de uma das autoras do presente texto. Trata-se de uma pesquisa de campo que foi realizada em uma escola com alto índice de busca por serviços de apoio da secretaria municipal de educação devido a queixas relacionadas ao comportamento das crianças.

Iniciaremos analisando o conteúdo de um projeto que foi elaborado pela equipe escolar como uma das estratégias para solucionar o problema relativo ao comportamento de alguns alunos e alunas, visto como inadequado pela equipe escolar. O título do projeto era "Gentileza gera gentileza" e sua justificativa estava assim descrita no documento Plano de gestão 2015 , elaborado pela equipe escolar e cujo conteúdo foi objeto de análise em Silva (2017):

[...] diante de uma sociedade individualista, materialista, optamos por desenvolver um projeto voltado para o resgate de valores [grifo nosso], conscientizando os alunos e a comunidade sobre a importância do respeito ao próximo e às diferenças, trazendo como objetivos 1) incentivar o ato de ser gentil entre funcionários, alunos e comunidade como reflexo do comportamento; 2) resgatar e vivenciar atos de boa convivência; 3) perceber a importância do outro em nossa vida; 4) incluir a natureza como estímulo ao olhar para o outro (Silva, 2017).

De antemão, ressaltamos que o projeto mostra o esforço da equipe escolar para organizar uma ação sistematicamente voltada para solucionar os problemas associados ao comportamento de alunos e alunas, intensamente vivenciados no cotidiano, inserindo um plano de ações especificamente voltado para esse fim no planejamento anual.

É importante notar que a afırmação: "diante de uma sociedade individualista, materialista, optamos por desenvolver um projeto voltado para o resgate de valores" denota o reconhecimento da existência de relações entre o comportamento individual e o contexto social mais amplo, bem como o reconhecimento de que as práticas educativas adotadas pela escola podem contribuir para alterar a conduta individual.

Destacamos, ainda, o trecho "conscientizando os alunos e a comunidade sobre a importância do respeito ao próximo" para evidenciarmos a incoerência entre o conteúdo a ser ensinado e as condições que caracterizam o funcionamento do psiquismo de parte significativa do público-alvo do projeto: os alunos. Considerando que se trata de crianças de 0 a 5 anos, o uso do verbo "conscientizar" indica a centralidade da linguagem verbal que, de acordo com a perspectiva histórico-cultural do desenvolvimento, é inapropriada, pois: "A primeira fase do desenvolvimento do pensamento, própria aos anos iniciais de vida, caracteriza-se pela indefinição do significado da palavra e, consequentemente, por seu limite como signo relacionado à percepção sensível (Martins, 2013b, p. 136).

Ou seja, apesar da relevância do conteúdo abordado no projeto, observa-se que a forma escolhida se mostra ineficaz para o destinatário em questão. A análise das estratégias didáticas propostas, apresentadas abaixo, nos permite um aprofundamento sobre essa inadequação:

Rodas de conversa, contação de história com fantoches construídos pelos educadores, música, brincadeiras de roda, desenho e brincadeiras afetivas. Ao participarem das rotinas de banho, sono e refeição serão trabalhadas a autonomia, respeitando a auto-estima, entre outros valores. As atividades envolvem valores como respeito, amizade, humildade, honestidade, responsabilidade, bondade, amor e gratidão, coragem, paciência e as questões de "por favor", "muito obrigado", "me desculpe" e "com licença" (Silva, 2017, p. 56).

Ao propor estratégias como: roda de conversa, contação de história com fantoches, músicas, brincadeiras de roda e desenho, percebe-se a centralidade atribuída à linguagem pela 


\section{MLE INTERACÃO EM PSICOLOGIA}

equipe escolar como principal forma para sanar o problema relacionado ao comportamento das crianças. Trata-se de uma abordagem que epistemologiza o processo de formação de valores, reiterando a cisão entre afeto e cognição ao enfatizar a repetição verbal de condutas esperadas como principal forma de promover mudanças no comportamento das crianças.

Como vimos, a análise do processo de formação das características individuais na psicologia histórico-cultural invalida quaisquer estratégias que tomem afeto e cognição como processos paralelos cuja expressão no psiquismo se dê por soma de um sobre o outro. De outro modo, Vygotski (2001) afirma a unidade afetivo-cognitiva como característica fundante do funcionamento do psiquismo e reitera que os saltos qualitativos que levam a mudanças na conduta individual só se efetivam mediante atividades desenvolvidas em relações sociais que requeiram novos modos de agir (Martins, 2013b).

Destacamos, ainda, no projeto em análise, a atividade descrita no referido documento como: "dia do vamos dividir o brinquedo? A criança trará um brinquedo para emprestar para o amigo, para trabalhar o conceito de dividir com calma e paciência" (Silva, 2017, p. 56). Essa atividade remete-nos a uma contradição presente no cotidiano da educação infantil relacionada à intencionalidade social que orienta a adoção dos atos educativos realizados pelos professores que atuam junto à primeira infância.

A referida contradição configura-se na medida que, de modo geral, é muito frequente, como estratégia de trabalho com crianças no primeiro ano de vida, a ênfase na identificação de seus pertences. Cabe considerar que a intencionalidade orientadora dos atos educativos voltados para esse fim, vincula-se à valoração positiva que é atribuída à propriedade privada na sociedade vigente. É justamente esse processo que produz como efeito a necessidade de "ensinar a dividir com calma e paciência", pois, se inicialmente os atos educativos contribuíram para a atribuição de uma valoração positiva para o apego aos pertences individuais, posteriormente, impõe-se a necessidade de "corrigir" as atitudes relacionadas a esse apego, cujo efeito colateral é a ausência de repertório de partilha de objetos entre os bebês.

Por fim, analisaremos a cena descrita abaixo que corresponde a uma das situações observadas em Silva (2017):

No refeitório, Vítor (nome fictício) estava sentado em uma mesa com mais duas meninas e um menino. Ele começou a se balançar, fazendo uso da cadeira como se fosse uma cadeira de balanço. A professora (aqui chamada de Dora) pediu que ele parasse de fazer isso, dizendo que ele poderia cair e se machucar. Vitor atendeu o pedido de Dora no momento em que ela falou, porém, alguns minutos depois, voltou a realizar o mesmo movimento com a cadeira. Uma das meninas que estava sentada na mesa ao lado de Vítor, se aproximou de Dora e falou: "Olha!". Dora se aproximou no momento em que a cadeira tombou para trás e Vítor começou a chorar. A menina, que estava chamando Dora para ver o que Vítor fazia, olhou para Vítor e disse: "Tá vendo? 0 deus castiga". Dora aproximou-se de Vítor e arrumou ele na cadeira dizendo que havia avisado que isso iria acontecer. 0 café foi servido, mas Vítor não quis se alimentar. Após levantar-se do tombo, Vitor ficou sentado, apoiado sobre o próprio braço até o momento em que Dora mandou que a turma se levantasse para ir para a escovação (p. 293).

Optamos por apresentar a cena na íntegra por considerar que o encadeamento dos atos manifestos na situação faz-se necessário para dar concreticidade à conduta que será destacada em nossa análise. No que diz respeito ao processo de formação de valores, assinalamos a atitude da menina que, além de insistir em apontar para a professora que um de seus colegas não estava atendendo às orientações dadas, dirige-se ao menino caído no chão e chorando em tom vingativo, manifesto por meio de conteúdo religioso.

Cabe informar que se trata de um grupo de crianças de 3 a 4 anos para ressaltar que, mesmo em tenra idade, as crianças podem manifestar atitudes cruelmente vinculadas ao processo de valoração vigente nesta sociedade, no caso explicitado, a valoração positiva da punição. Observa-se que a atuação da professora, por sua vez, centra-se em intervir na conduta do menino e acaba por reforçar a falta de empatia manifesta pela menina.

Retomamos a afirmação de que a intencionalidade orienta todos os atos humanos e a posição que o professor ocupa na relação com os alunos torna seus atos significativos na formação de alunos e alunas visto que:

Para que a criança se esforce na sua vontade, é necessário que o objetivo marcado pelo adulto ou pela própria criança seja desejável, que procure realmente atingi-lo. É sabido que os sentimentos são a forma específica em que o indivíduo reflecte a realidade. Nos sentimentos encontram a sua expressão no grau em que se vêem satisfeitas as necessidades mais complexas e variadas que foram educadas no indivíduo. Os sentimentos exprimem a atitude da pessoa para com aquilo que a rodeia.

A importância dos motivos que impulsionam as acções volitivas da criança está intimamente vinculada à educação dos sentimentos, sem os quais não se deve falar em desenvolvimento da vontade consciente e educada no aspecto moral (Liublinskaia, 1979, p. 353).

Sendo assim, Liublinskaia (1979) contribui para compreendermos que a atuação da professora na situação descrita, ainda que ela não tivesse essa intenção em primeiro plano na sua consciência, contribui para a manutenção da postura de superioridade da menina e para sua falta de sensibilidade em 


\section{MLE INTERACÃO EM PSICOLOGIA}

relação ao sofrimento manifesto por seu colega. Além disso, ao reforçar a atitude punitiva da menina, a professora contraria os valores que a equipe escolar afirma querer formar no projeto apresentado inicialmente

Trata-se de exemplos concretos que elucidam as relações entre ato educativo em contexto escolar e o processo de formação de valores até aqui discutido. As táticas didáticas apresentadas evidenciam o descompasso entre as intenções anunciadas pela equipe escolar no projeto e as estratégias adotadas, tanto nas atividades propostas no projeto, quanto nos atos manifestados nas situações cotidianas.

Reiteramos nossa defesa em relação à especificidade da educação escolar na formação do psiquismo, tendo em vista que:

A educação escolar aqui defendida é um processo que interfere diretamente na formação dos educandos, cientes de que os conteúdos dos próprios sentimentos outra coisa não são, senão conceitos. Na mesma medida, cientes também de que os conteúdos escolares mobilizadores dos pensamentos incluem "sentimentos intelectuais", isto é, os sentimentos mobilizados pela atividade intelectual requerida na construção do conhecimento. Uma educação escolar apta, portanto, à formação e promoção de sentimentos intelectuais positivos, imprescindíveis tanto na atividade de quem aprende quanto na de quem ensina (Martins, 2013b, p. 306).

Para tanto, faz-se necessário que as atividades desenvolvidas na escola estejam voltadas para o cumprimento de sua função principal, relacionada à transmissão de conhecimentos que se tornaram universais por contribuir para compreensão da realidade humana, enriquecendo os conceitos científicos de sentido e os conceitos cotidianos de sistematicidade. Como vimos, é na garantia da indissociabilidade da tríade conteúdo-forma-destinatário, tanto no registro do planejamento pedagógico, quanto na consciência do professor, que cada ato educativo estará, intencionalmente, voltado para essa finalidade.

\section{CONSIDERAÇÕES FINAIS}

0 percurso de análise que apresentamos representa nosso esforço para enfrentar um problema que se configura como um verdadeiro drama para a profissão docente, sustentado pela falsa dicotomia entre educar e ensinar. Em face desse desafio, buscamos desvelar determinações e relações que se interpõe como elos que unem a função social da educação escolar e a dinâmica de formação emocional dos indivíduos, que alicerça as tendências configuradas como traços do seu caráter e repercute no processo de formação de seus valores pessoais.
A análise desses elos revelou que a interferência da educação escolar na formação de cada aluno ocorre transversalmente na atividade escolar em sua totalidade, portanto, a eficácia das estratégias que visam abordar esse conteúdo como componente curricular pode ter um êxito pontual, porém não assegura a mudança de conduta do aluno. Como mostramos, o aprimoramento do processo de formação de valores em contexto escolar coincide com o aprimoramento do próprio trabalho pedagógico em sua função precípua, qualificando o processo de formação de conceitos científıcos e direcionando seus efeitos na formação do autodomínio da conduta dos educandos.

Destacamos a intencionalidade dos atos educativos como fator interveniente na formação de valores, pois orienta a concretização da dinâmica entre forma e conteúdo na execução dos atos que o professor dirige ao aluno. Diante disso, defendemos que um posicionamento intencionalmente voltado para a formação de outro tipo de ser humano, capaz de produzir outras relações sociais, requer o vislumbre de outra organização social que só pode se efetivar a partir da compreensão de que a sociedade vigente é uma forma particular de organização social e não a única possível para a humanidade.

Essa visão abre para o professor a possibilidade de romper com a atribuição de valoração positiva para um conjunto de características típicas de relações sociais fundadas no antagonismo de classes, como o individualismo e a meritocracia, por exemplo. Enfım, vislumbrar em cada aluno e aluna um novo tipo de ser humano possibilitará a transformação de seus atos educativos em compromisso com uma sociedade em que se privilegie a transmissão da valoração positiva em relação aos interesses coletivos gerais como condição para o efetivo desenvolvimento dos indivíduos.

\section{CONTRIBUIÇÃO DE CADA AUTOR}

Certificamos que todos os autores participaram suficientemente do trabalho para tornar pública sua responsabilidade pelo conteúdo. A contribuição de cada autor pode ser atribuída como se segue:

CRS contribuiu com o estudo e redação do texto.

JMR contribuiu com a tradução do resumo e revisão de forma e conteúdo.

\section{DECLARAÇÃO DE CONFLITOS DE INTERESSE}

Os autores declaram que não há conflitos de interesse no manuscrito submetido. 


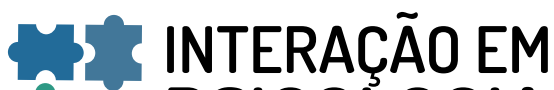 ET PSICOLOGIA}

\section{REFERÊNCIAS}

Base Nacional Comum Curricular. Ministério da Educação. (2017). http://basenacionalcomum.mec.gov.br/wp-content/uploads/2018/02/bncc-20dez-site.pdf.

Coutinho, C. N. (2010). O Estruturalismo e a Miséria da Razão. (2 ed.). Expressão Popular.

Krutetski, V. A. (1960). El caráter. In: Smirnov, A. A.; Leontiev A. N.; Rubinstein, S. L. - Tieplov, B. M. Psicología. (pp. 462489). Grijalbo.

Liublinskaia, A. (1979). O desenvolvimento psíquico da criança. Editorial Notícias.

Martins, L. M. (2013a). Os fundamentos psicológicos da pedagogia histórico-crítica e os fundamentos pedagógicos da psicologia histórico-cultural. Germinal: Marxismo E Educação Em Debate, 5(2), 130-143. http://dx.doi.org/10.9771/ gmed.v5i2.9705

Martins, L. M. (2013b). O desenvolvimento do psiquismo e a Educação Escolar: contribuições à luz da psicologia histórico-cultural e da pedagogia histórico-crítica. Autores Associados.

Marx, K. (1845). Teses sobre Feuerbach. Arquivo Marxista na Internet. https://www.marxists.org/portugues/ marx/1845/tesfeuer.htm

Rosa, J. M. (2018). A apropriação dos princípios fundamentais da teoria da evolução e os alcances abstrativos na concepção de mundo. [Tese de doutorado, Universidade Estadual Paulista Júlio de Mesquisa Filho]. rosa_jm_dr_ arafcl.pdf (1.902Mb). https://repositorio.unesp.br/handle/11449/157252
Saviani, D. (2002). Educação: do senso comum à consciência filosófica. (14 ed.) Autores Associados.

Saviani, D. (2005). Pedagogia histórico-crítica: primeiras aproximações. (9 ed.) Autores Associados.

Saviani, D. (2015). Debate sobre educação, formação humana e ontologia a partir da questão do método dialético. In: Saviani, D.; Duarte, N. (Org.). Pedagogia histórico-crítica e luta de classes na educação escolar. (pp. 223-290). Autores Associados.

Silva, C. R. (2017). Análise da dinâmica de formação do caráter e a produção da queixa escolar na educação infantil: contribuições à luz da psicologia histórico-cultural e da pedagogia histórico-crítica. [Tese de doutorado, Universidade Estadual Paulista Júlio de Mesquita Filho]. silva_cr_dr_arafcl_sub.pdf (3.030Mb). https://repositorio.unesp.br/handle/11449/152064

Silva, M. M. (2018). A formação de competências socioemocionais como estratégia de captura da subjetividade da classe trabalhadora. [Tese de Doutorado em Educação Escolar, Universidade Estadual Paulista "Júlio de Mesquita Filho", Faculdade de Ciências e Letras (Campus Araraquara)]. silva_mm_dr_arafcl.pdf (1.569Mb). https://repositorio. unesp.br/handle/11449/157212

Vygotski, L. S. (2001). Obras escogidas. Tomo II. Madrid Visor

Vygotski, L. S. (2006). Sobre a questão da dinâmica do caráter infantil. Linhas Críticas, 12(23), 279-292. https://doi. org/10.26512/lc.v12i23.3327

Submetido em: $22 / 04 / 20$ $1^{\text {a }}$ decisão editorial em: $12 / 06 / 20$ Aprovado em: 20/07/20 